\title{
The production of carbon materials by hydrothermal
}

\section{carbonization of cellulose}

\author{
M. Sevilla ${ }^{* a}$ and A. B. Fuertes ${ }^{a}$

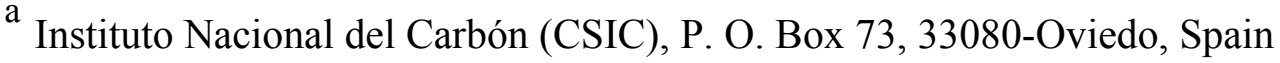

\begin{abstract}
Highly functionalized carbonaceous materials were produced by means of the hydrothermal carbonization of cellulose at temperatures in the $220-250^{\circ} \mathrm{C}$ range. The formation of this material follows essentially the path of a dehydration process, similar to that previously observed for the hydrothermal transformation of saccharides such as glucose, sucrose or starch. The materials so formed are composed of agglomerates of carbonaceous microspheres (size $\sim 2-5 \mu \mathrm{m}$ ), as evidenced by SEM. The combination of the results of the elemental analysis with that obtained by different spectroscopic techniques (infrared and Raman spectroscopy, and XPS) has allowed us to inferred that, from a chemical point of view, the solid product consists of small clusters of condensed benzene rings that form stable groups with oxygen in the core (i. e. ether, quinone, pyrone), whereas the shell possesses more reactive/hydrophilic oxygen functionalities (i. e. hydroxyl, carbonyl, carboxylic, ester).
\end{abstract}

Corresponding author. Fax: +34985297662, E-mail: martasev@incar.csic.es (M Sevilla) 


\section{Introduction}

The thermal treatment of water mixed with organic substances such as saccharides (glucose, sucrose or starch) or simpler compounds such as furfural at temperatures in the $150-350^{\circ} \mathrm{C}$ range (autogenous pressure) gives rise to water-soluble organic substances and a carbon-rich solid product. This process, termed hydrothermal carbonization, has generated widespread interest in recent years [1-6]. However, the hydrothermal treatment of saccharides is not a new process. Experiments involving the hydrothermal carbonization of different types of saccharides were carried out during the first half of the twentieth century in order to obtain information about the mechanism of natural coalification [7-9]. Later on, numerous papers dealing with the hydrothermal treatment of cellulose to obtain liquid fuel or chemicals appeared [10-14]. Not until recently, however, has any attention been paid to the solid residue resulting from this treatment. Wang et al. were the first to report on the hydrothermal treatment of sucrose as a way to produce carbonaceous microspheres (size $\sim 1.5 \mu \mathrm{m}$ ) [1]. Subsequently, Sun and $\mathrm{Li}$ reported on the preparation of carbonaceous microspheres of a tunable size $(0.2-$ $1.5 \mu \mathrm{m})$ loaded with noble-metal nanoparticles [3]. Other groups have taken advantage of the oxygen functionalities present on the outer surface of the carbonaceous microspheres and employed them as sacrificial templates to fabricate hollow spheres of inorganic materials $\left(\mathrm{Ga}_{2} \mathrm{O}_{3}, \mathrm{GaN}, \mathrm{WO}_{3}, \mathrm{SnO}_{2}\right.$, etc) [3, 15-19]. We have previously investigated the use of carbonaceous microspheres produced by the hydrothermal carbonization of glucose, sucrose and starch as precursors for the production of graphitic carbon nanostructures and the application of these nanocarbons as electrocatalyst supports [20,21].

Among the potential saccharides that can be employed to produce carbonaceous materials through hydrothermal carbonization, cellulose is the most promising material 
as it is by far the most abundant and inexpensive saccharide available. Although several authors have reported using cellulose for the production of carbon materials by means of pyrolysis at high temperatures [22-24], to the best of our knowledge, no one has employed cellulose to produce carbonaceous materials by means of hydrothermal carbonization. In the present work we investigate the potential of cellulose as precursor for the production of highly functionalized carbonaceous materials via hydrothermal carbonization. The chemical and structural characteristics of the hydrothermally carbonized products are also investigated.

\section{Experimental}

\subsection{Hydrothermal treatment of cellulose}

The hydrothermal carbonization of cellulose was carried out according to the following procedure. Between 2 and $16 \mathrm{~g}$ of cellulose (Aldrich) was dispersed in water $(50 \mathrm{~mL})$ and stirred for 4 hours. The ratio volume of solution/volume of autoclave is around 0.3 . The mixture was then transferred to a stainless steel autoclave fitted with a stirring mechanism, heated up to a temperature in the $200-250^{\circ} \mathrm{C}$ range and maintained at this temperature for 2 or 4 hours. The resulting solid product (here denoted as hydrochar) was recovered by filtration and washed with abundant distilled water. Then, it was dried at $120^{\circ} \mathrm{C}$ for 4 hours. The experimental conditions (concentration, temperature and time) used in these experiments are listed in Table 1. The codes used to identify the hydrochar samples are also indicated in this table.

\subsection{Characterization methods}

Scanning electron microscopy (SEM) microphotographs were obtained with a Zeiss DSM 942 microscope. Diffuse reflectance infrared (IR) spectra of the powders of the materials were recorded on a Nicolet Magna-IR 560 spectrometer fitted with a diffuse reflection attachment. The Raman spectra were recorded on a Horiva (LabRam HR-800) 
spectrometer. The source of radiation was a laser operating at a wavelength of $514 \mathrm{~nm}$ and a power of $25 \mathrm{~mW}$. X-ray photoelectron spectroscopy (XPS) was carried out by means of a Specs spectrometer, using $\mathrm{MgK} \alpha(1253.6 \mathrm{eV})$ radiation from a double anode at $50 \mathrm{w}$. Binding energies for the high-resolution spectra were calibrated by setting $\mathrm{C} 1 \mathrm{~s}$ to $284.6 \mathrm{eV}$. Adsorption measurements were performed using an ASAP 2020 (Micromeritics) volumetric adsorption system. The thermogravimetric experiments were carried out in a C.I. Electronics analyser. Elemental analysis (C, H and O) of the samples was carried out on a LECO CHN-932 microanalyzer.

\section{Results and discussion}

\subsection{Structural properties}

Figure 1 shows SEM images of the cellulose (Fig. 1a) and products obtained by hydrothermal treatment at $210^{\circ} \mathrm{C}$ (Fig. 1b), $220^{\circ} \mathrm{C}$ (Fig. 1c), $230^{\circ} \mathrm{C}$ (Fig. 1d) and $250^{\circ} \mathrm{C}$ (Figs. 1e and 1f). It should be noted that, whereas the products from hydrothermal treatment at $210^{\circ} \mathrm{C}$ exhibit an irregular morphology similar to that of pristine cellulose, the samples obtained at temperatures $\geq 220{ }^{\circ} \mathrm{C}$ consist mainly of aggregates of microspheres with a diameter in the $2-10 \mu \mathrm{m}$ range. The SEM images (Fig. 1) evidence that there is an abrupt morphological change in the $210-220^{\circ} \mathrm{C}$ range. These results suggest that the onset of the hydrothermal reactions for the cellulose occurs at around $220^{\circ} \mathrm{C}$. This conclusion is confirmed by the effect that hydrothermal treatment has upon the microcrystalline structure of cellulose. Thus, pristine cellulose exhibits three characteristic peaks, as shown in Figure 2. The (101) and (002) reflections are caused by the transverse arrangement of the crystallites in cellulose I, while reflection (004) is related to the longitudinal structure of the polymer [25]. It is observed that when cellulose is hydrothermally treated at $210^{\circ} \mathrm{C}$, the resulting material exhibits a XRD pattern similar to that of pristine cellulose, indicating that the microcrystalline structure 
of the cellulose has been preserved. In contrast, the samples obtained at temperatures $\geq$ $220^{\circ} \mathrm{C}$ are no longer crystalline, as can be deduced from the absence of reflections in the XRD pattern (see Figure 2). These results evidence that the onset of hydrothermal carbonization takes place at around $220^{\circ} \mathrm{C}$. This is also confirmed by the FTIR spectra corresponding to the hydrochar samples obtained at different temperatures, as will be discussed in the next section. The temperature for the onset of hydrothermal carbonization of cellulose is considerably higher than for glucose, sucrose or starch $\left(\sim 160-170^{\circ} \mathrm{C}\right)[26,27]$. The strong resistance of the cellulose to decompose is a consequence of the fact that the hydroxyl groups of the glucose residues present in the structure of the cellulose form hydrogen bonds that hold the polymeric chains firmly together and side-by-side $[28,29]$.

Analysis of the textural properties of the cellulose-derived hydrochar samples shows that they have a poor porosity, as evidenced by the $\mathrm{N}_{2}$ adsorption isotherm obtained for the CE-2 sample (see Figure S1 in Supplementary Information). This sample has a BET surface area of $30 \mathrm{~m}^{2} \cdot \mathrm{g}^{-1}$, which matches well with the external surface area determined by the $\alpha_{\mathrm{s}}$-plot technique $\left(26 \mathrm{~m}^{2} \cdot \mathrm{g}^{-1}\right)$ (see inset in Figure $\left.\mathrm{S} 1\right)$.

\subsection{Chemical characteristics}

The hydrothermal carbonization of the cellulose leads to an increase in the carbon content of the solid residue from $44.4 \mathrm{wt} \%$ (cellulose) to $70.7-72.5 \mathrm{wt} \%$ in the hydrochar samples (see Table 1). At the same time, there is a reduction in the oxygen and hydrogen contents. These variations are consistent with the formation of a wellcondensed material. Thus, analysis of the change in weight loss (Figure S2a) and the rate of weight loss (Figure S2b) with temperature (measured under an inert atmosphere) for the hydrochar samples shows that the decomposition of this material takes place in a temperature range of $\sim 300-700^{\circ} \mathrm{C}$, which is typical of highly condensed carbonaceous 
materials such as coal [30]. This behaviour contrasts with that observed for the pyrolysis of pure cellulose, which occurs suddenly at the relatively low temperature of $\sim$ $300^{\circ} \mathrm{C}$ (see Figure S2). It was also observed that an increase in the temperature of hydrothermal carbonization (i. e. from 230 to $250^{\circ} \mathrm{C}$ ) causes a decrease in the $\mathrm{O} / \mathrm{C}$ and $\mathrm{H} / \mathrm{C}$ atomic ratios (see Table 1), suggesting an increase in the degree of condensation of the hydrochar products. Moreover, shorter reaction times or higher concentrations of cellulose lead to less condensed products (high $\mathrm{O} / \mathrm{C}$ and $\mathrm{H} / \mathrm{C}$ atomic ratios). The variation in the elemental composition of the materials (from cellulose to hydrochar products) was analyzed with the aid of the Van Krevelen diagram (see Figure 3) [31], which shows that the evolution of the $\mathrm{H} / \mathrm{C}-\mathrm{O} / \mathrm{C}$ atomic ratios from cellulose to hydrochar follows essentially the path of a dehydration process, similar to that previously observed for the hydrothermal transformation of saccharides such as glucose, sucrose or starch [26].

The product yields (grams of hydrochar per 100 grams of cellulose) obtained from the hydrothermal carbonization are in the $30-50 \mathrm{wt} \%$ range (see Table 1). The percentages of carbon retained in the final solid product are also listed in Table 1. It can be seen that, depending on the operational conditions, the carbon present in the cellulose retained in the hydrochar products is in the $54-84 \mathrm{wt} \%$ range, while the rest mainly remains in the organic compounds that are dissolved in the aqueous phase (i. e. furfural, 5-hydroxymethylfurfural, organic acids, aldehydes, etc) [32-35]. It should be noted that for a carbonization temperature of $250^{\circ} \mathrm{C}$ and high concentrations of cellulose $(>160$ $\mathrm{g} \cdot \mathrm{L}^{-1}$ ), the percentage of carbon fixed in the hydrochar is $\sim 70-80 \%$. Taking into account the recalcitrant nature of carbon contained in the hydrochar (high resistance to be mineralised due to the microbial action), the above result suggests that the hydrothermal 
carbonization of cellulose is an effective way to increases the turnover time of the carbon contained in the biomass.

The chemical transformations that occur when the cellulose is converted into carbonaceous products by means of hydrothermal carbonization were examined by several spectroscopic techniques. FTIR spectra of the hydrochar samples and cellulose are shown in Figure 4. It can be seen that the FTIR spectra of the sample hydrothermally treated at $210^{\circ} \mathrm{C}$ is similar to that of the cellulose, confirming that no chemical transformation occurs when the cellulose is heat-treated at $<220^{\circ} \mathrm{C}$. In contrast, the samples obtained at $\geq 220^{\circ} \mathrm{C}$ exhibit completely different FTIR traces (see Figure 4). The spectra corresponding to the hydrochar samples obtained at $\geq 220^{\circ} \mathrm{C}$ are very similar. They contain several bands which reveal that aromatization processes take place during hydrothermal carbonization. The presence of aromatic rings is also evidenced by the band at $1620 \mathrm{~cm}^{-1}$, attributed to $\mathrm{C}=\mathrm{C}$ vibrations $[27,36]$, and to the bands in the $875-750 \mathrm{~cm}^{-1}$ region, assigned to aromatic $\mathrm{C}-\mathrm{H}$ out-of-plane bending vibrations [37]. These hydrochar materials also possess aliphatic structures, as can be deduced from the band at $3000-2815 \mathrm{~cm}^{-1}$, which corresponds to stretching vibrations of aliphatic $\mathrm{C}-\mathrm{H}[38,39]$. Moreover, the presence of oxygen groups is suggested by the bands at: $3000-3700 \mathrm{~cm}^{-1}$ (a wide band attributed to $\mathrm{O}-\mathrm{H}$ stretching vibrations in hydroxyl or carboxyl groups) [38], $1710 \mathrm{~cm}^{-1}(\mathrm{C}=\mathrm{O}$ vibrations corresponding to carbonyl, quinone, ester or carboxyl) [35] and 1000-1460 $\mathrm{cm}^{-1}$ (C-O stretching vibrations in hydroxyl, ester or ether and $\mathrm{O}-\mathrm{H}$ bending vibrations) [35]. The decrease (in relation to raw cellulose) in the intensity of the bands at $1000-1460 \mathrm{~cm}^{-1}$ and the broad band at $3000-3700 \mathrm{~cm}^{-1}$ suggest that dehydration occurred during the hydrothermal carbonization of the cellulose, confirming our analysis of the evolution of the $\mathrm{O} / \mathrm{C}-\mathrm{H} / \mathrm{C}$ atomic ratios based on the Van Krevelen diagram (see Figure 3). 
In order to check the presence of aromatic structures in the hydrochar products, Raman spectroscopy analysis was performed. The Raman spectrum obtained for the CE-4 hydrochar sample is presented in Figure 5a. For purposes of comparison, the same figure shows the spectrum obtained for the CE-4 sample carbonized at $800^{\circ} \mathrm{C}\left(1 \mathrm{~h}, \mathrm{~N}_{2}\right.$ atmosphere). Both spectra are characteristic of carbonized materials $[40,41]$ and they differ completely from that of the cellulose (see inset of Figure 5a). Thus, the carbonized samples exhibit two broad overlapping bands at around 1360 (D-mode) and 1587 (G-mode) $\mathrm{cm}^{-1}$, which reveal the presence of $\mathrm{C} \mathrm{sp}^{2}$ atoms in benzene or condensed benzene rings of amorphous (partially hydrogenated) carbon [42, 43]. Small aromatic clusters must therefore be present in the hydrochar samples. This corroborates the presence of aromatic structures in the hydrochar materials and in turn confirms the results deduced by FTIR.

The oxygen functional groups present on the outer layer of the hydrochar particles were investigated by X-ray photoelectron spectroscopy (XPS). A representative C 1s core level spectrum obtained for the CE-3 is shown in Figure $5 \mathrm{~b}$. The $\mathrm{C} 1 \mathrm{~s}$ spectrum of the rest of the samples is similar to the one showed. It contains four signals attributed, respectively, to the aliphatic/aromatic carbon group $\left(\mathrm{CH}_{\mathrm{x}}, \mathrm{C}-\mathrm{C} / \mathrm{C}=\mathrm{C}\right)(284.6 \mathrm{eV})$, hydroxyl groups (-C-OR) $(285.7 \mathrm{eV})$, carbonyl groups $(>\mathrm{C}=\mathrm{O})(287.3 \mathrm{eV})$ and carboxylic groups, esters or lactones (-COOR) (289.2 eV) [44-46]. These results show that there is an abundance of oxygen groups in the shells of the particles. A comparison of the $(\mathrm{O} / \mathrm{C})$ atomic ratios determined by elemental analysis (see Table 1) with those calculated by XPS (0.282 and 0.275 for the CE- 2 and CE-3 samples, respectively) shows that the $(\mathrm{O} / \mathrm{C})$ atomic ratios in the core and in the shell of the particles are quite similar. This indicates that there is a high concentration of oxygen in the inner part of the hydrochar particles. We believe that the oxygen groups present in the core differ 
from those in the shell. Whereas the oxygen in the core forms stable groups (i. e. ether, quinone, pyrone, etc), whereas the oxygen functionalities in the outer layer consist of more reactive/hydrophilic groups (i. e. hydroxyl, carbonyl, carboxylic, ester, etc), as reflect in the XPS analysis.

\subsection{The formation of hydrochar from cellulose}

There are numerous works on the chemical transformations that take place when cellulose is treated under pressure in sub- or supercritical water in the literature [47-49]. From this information it is possible to reconstruct the mechanism of the formation of hydrochar products from cellulose. This is schematically illustrated in Figure 6. In a first step, when a cellulose aqueous dispersion is hydrothermally treated at temperatures $>220^{\circ} \mathrm{C}$, the cellulose chains hydrolize. At this stage, the hydronium ions generated by water autoionization catalyse the hydrolysis of cellulose giving rise to different oligomers (cellobiose, cellohexaose, cellopentaose, cellotetraose and cellotriose) and glucose [48, 49], which subsequently isomerizes to form fructose [29, 52]. The decomposition of the monomers produces organic acids (acetic, lactic, propenoic, levulinic and formic acids) $[29,53]$, the hydronium ions formed from these acids being the catalysts of the degradation in subsequent reaction stages [54]. The oligomers also hydrolyze into their monomers, which undergo dehydration and fragmentation reactions (i.e. ring opening and $\mathrm{C}-\mathrm{C}$ bond breaking) leading to the formation of different soluble products, such as 1,6-anhydroglucose, erythrose, furfural-like compounds (i.e. 5hydroxymethylfurfural, furfural, 5-methylfurfural), the hydroxymethylfurfural-related 1,2,4-benzenetriol, acids and aldehydes (acetaldehyde, acetonylacetone, glyceraldehyde, glycolaldehyde, pyruvaldehyde) [34, 35, 47, 54-57]. The decomposition of the furfurallike compounds also generates acids/aldehydes and phenols [49]. The subsequent reaction stages consist of polymerization or condensation reactions, which lead to the 
formation of soluble polymers [56]. These reactions may be induced by intermolecular dehydration or aldol condensation. At the same time, the aromatization of polymers takes place. $\mathrm{C}=\mathrm{O}$ groups appear due to the dehydration of water from the equatorial hydroxyl groups in the monomers [58]. Alternatively, the $\mathrm{C}=\mathrm{C}$ bonds (see Figure 4) may result from the keto-enol tautomerism of dehydrated species or from intramolecular dehydration [58]. Aromatic clusters may be produced by the condensation (by intermolecular dehydration) of the aromatized molecules generated in the decomposition/dehydration of the oligosaccharides or monosaccharides. When the

concentration of aromatic clusters in the aqueous solution reaches the critical supersaturation point, a burst nucleation takes place. The nuclei so formed grow outwards by diffusion towards the surface of the chemical species present in the solution. These species are linked to the surface of the microspheres via the reactive oxygen functionalities (hydroxyl, carbonyl, carboxylic, etc) present in both the outer surface of the particles and in the reactive species. As a result of this linkage, stable oxygen groups such as ether or quinone are formed. Under these circumstances, once the growth process stops, the outer surface of the hydrochar particles will contain a high concentration of reactive oxygen groups, whereas the oxygen in the core forms less reactive groups.

\section{Conclusions}

In summary, we have presented a procedure for obtaining a carbonaceous product, denoted here as hydrochar, by means of the hydrothermal carbonization of cellulose. The hydrochar is made up of micrometer sized spheres (size $\sim 2-10 \mu \mathrm{m}$ ). The onset of carbonization under hydrothermal conditions takes place between $210^{\circ} \mathrm{C}$ and $220^{\circ} \mathrm{C}$. From a chemical point of view, the hydrochar contains a high amount of oxygen $(\sim 23$ 24 wt $\%$ of oxygen), which is present both in the core and in the shell of the 
carbonaceous microspheres. However, the nature of the oxygen groups in the core and shell differs, as inferred from XPS and FTIR measurements. Indeed, the oxygen in the inner part of the microspheres probably consists of less reactive groups (i. e. ether, quinone, pyrone), whereas the shell mainly contains more reactive/hydrophilic (i. e. hydroxyl, carbonyl, carboxylic, ester) oxygen functionalities.

According to the mechanism proposed here, the formation of hydrochar takes place via: i) hydrolysis of cellulose chains, ii) dehydration and fragmentation into soluble products of the monomers that come from the hydrolysis of cellulose, iii) polymerization or condensation of the soluble products, iv) aromatization of the polymers thus formed, v) appearance of a short burst of nucleation and vi) growth of the nuclei so formed by diffusion and linkage of species from the solution to the surface of the nuclei.

Acknowledgments. The financial support for this research work provided by the Spanish MCyT (MAT2008-00407) is gratefully acknowledged. M.S. acknowledges the assistance of the Spanish MCyT for the award of a FPU grant.

\section{References}

[1] Wang Q, Li H, Chen L, Huang X. Monodispersed hard carbon spherules with uniform nanopores. Carbon 2001; 39(14): 2211-2214.

[2] Wang Q, Li H, Chen L, Huang X. Novel spherical microporous carbon as anode material for Li-ion batteries. Solid State Ionics 2002; 152-15: 43-50.

[3] Sun X, Li Y. $\mathrm{Ga}_{2} \mathrm{O}_{3}$ and GaN Semiconductor Hollow Spheres. Angew Chem Int Ed Engl 2004; 43(29): 3827-3831. 
[4] Titirici MM, Thomas A, Yu S-H, Müller J-O, Antonietti M. A Direct Synthesis of Mesoporous Carbons with Bicontinuous Pore Morphology from Crude Plant Material by Hydrothermal Carbonization. Chem Mater 2007; 19(17): 4205-4212.

[5] Hu J, Li H, Huang X. Influence of micropore structure on Li-storage capacity in hard carbon spherules. Solid State Ionics 2005; 176(11-12): 1151-1159.

[6] Yao C, Shin Y, Wang L-Q, Windish CF, Samuels WD, Arey BW, Wang C, Risen WM, Exarhos GJ. Hydrothermal Dehydration of Aqueous Fructose Solutions in a Closed System. J Phys Chem C 2007; 111(42): 15141-15145.

[7] Bergius F, Specht H. Die Anwendung hoher Drucke bei chemischen Vorgängen und eine Nachbildung des Entstehungsprozesses der Steinkohle; Verlag Wilhelm Knapp: Halle and der Saale, Germany, 1913; p. 58.

[8] Berl E, Schimdt A. Die Inkohlung von Cellulose und Lignin in neutralem Medium. Liebigs Annalen Chemie 1932, 493(1): 97-123.

[9] Schuhmacher JP, Huntjens FJ, Van Krevelen DW. Chemical Structure and properties of Coal XXVI-Studies on artificial coalification. Fuel 1960, 39, 223-234.

[10] Bobleter O, Niesner R, Röhr M. The Hydrothermal Degradation of Cellulosic Matter to Sugars and their Fermentative Conversion to Protein. J Appl Polym Sci 1976; 20(): 2083-2093.

[11] Bonn G, Cocin R, Bobleter O. Hydrothermolysis - a new process for the utilization of Biomass. Wood Sci Technol 1983; 17(3): 195-202.

[12] Karagöz S, Bhaskar T, Muto A, Sakata Y, Oshiki T, Kishimoto T. Lowtemperature catalytic hydrothermal treatment of wood biomass: analysis of liquid products. Chem Eng J 2005; 108(1-2): 127-137.

[13] Huber GW, Iborra S, Corma A. Synthesis of Transportation Fuels from Biomass: Chemistry, Catalysts, and Engineering. Chem Rev 2006;, 106(9): 4044-4098. 
[14] Sakaki, T, Shibata M, Miki T, Hirosue H. Hayashi N. Reaction model of cellulose decomposition in near-critical water and fermentation of products. Bioresource Technol 1996; 58(2): 197-202.

[15] Li, X-L, Lou T-J, Sun X-M, Li Y-D. Highly Sensitive $\mathrm{WO}_{3}$ Hollow-Sphere Gas ensors. Inorg Chem 2004, 43(17): 5442-5449.

[16] Zheng M, Cao J, Chang X, Wang J, Liu J, Ma X. Preparation of oxide hollow spheres by colloidal carbon spheres. Mater Lett 2006, 60(24): 2991-2993.

[17] Titirici MM, Antonietti M, Thomas A. A Generalized Synthesis of Metal Oxide Hollow Spheres Using a Hydrothermal Approach. Chem Mater 2006, 18(16): 38083812.

[18] Sun X, Liu J, Li Y. Use of Carbonaceous Polysaccharide Microspheres as Templates for Fabricating Metal Oxide Hollow Spheres. Chem Eur J 2006, 12(7): 20392047.

[19] Wang C, Xiangfeng C, Mingmei W. Highly sensitive gas sensors based on hollow $\mathrm{SnO} 2$ spheres prepared by carbon sphere template method. Sensors and Actuators B: Chemical 2007, 120(2): 508-513.

[20] Sevilla M, Lota G, Fuertes AB. Saccharide-based graphitic carbon nanocoils as supports for PtRu nanoparticles for methanol electrooxidation. J Power Sources 2007, 171(2): 546-551.

[21] Sevilla M, Sanchís C, Valdés-Solís T, Morallón E, Fuertes AB. Highly dispersed platinum nanoparticles on carbon nanocoils and their electrocatalytic performance for fuel cell reactions. Electrochim Acta 2008, 54(8):2234-2238.

[22] Ramosa ME, Bonellia PR, Cukiermana AL. Physico-chemical and electrical properties of activated carbon cloths: Effect of inherent nature of the fabric precursor. Colloids Surfaces A: Physicochem Eng Aspects 2008, 324(1-3): 86-92. 
[23] Guo Y, Rockstraw DA. Physical and chemical properties of carbons synthesized from xylan, cellulose, and Kraft lignin by H3PO4 activation. Carbon 2006, 44(8): 14641475.

[24] Guilminot E, Gavillon R, Chatenet M, Berthon-Fabryc S, Rigacci A, Budtovab T. New nanostructured carbons based on porous cellulose: Elaboration, pyrolysis and use as platinum nanoparticles substrate for oxygen reduction electrocatalysis. J. Power Sources 2008, 185(2): 717-726.

[25] Zavadskii AE. X-ray diffraction method of determining the degree of crystallinity of cellulose materials of different anisotropy. Fibre Chemistry 2004, 36(6): 425-430.

[26] Sevilla M, Fuertes AB. Chemical and structural properties of carbonaceous products obtained by hydrothermal carbonization of saccharides. Chem Eur J, In Press, DOI:10.1002/chem.200802097.

[27] Sun X., Li Y. Colloidal Carbon Spheres and Their Core/Shell Structures with Noble-Metal Nanoparticles. Angew Chem Int Ed Engl 2004, 43(5): 597-601.

[28] Shaka S, Ueno T. Chemical conversion of various celluloses to glucose and its derivatives in supercritical water. Cellulose 1999, 6(3): 177-191.

[29] Bobleter O. Hydrothermal degradation of polymers derived from plants. Prog Polym Sci 1994, 19(5): 797-841.

[30] Serageldin MA, Pan W-P. Coal analysis using thermogravimetry. Thermochim Acta 1984, 76(1-2): 145-160.

[31] Van Krevelen DW. Graphical statistical method for the study of structure and reaction processes of coal. Fuel 1950, 29, 269-284.

[32] Holgate HR, Meyer JC, Tester JW. Glucose hydrolysis and oxidation in supercritical water. AIChE J 1995, 41(3): 637-648. 
[33] Karagöz S, Bhaskar T, Muto A, Sakata Y. Comparative studies of oil compositions produced from sawdust, rice husk, lignin and cellulose by hydrothermal treatment. Fuel 2005, 84(7-8): 875-884.

[34] Aida TM, Sato Y, Watanabe M, Tarima K, Nonaka T, Hattori H, Arai K. Dehydration of d-glucose in high temperature water at pressures up to $80 \mathrm{MPa}$. $\mathrm{J}$ Supercritical Fluids 2007, 40(3): 381-388.

[35] Kabyemela BM, Adschiri T, Malaluan RM, Arai K. Glucose and Fructose Decomposition in Subcritical and Supercritical Water: Detailed Reaction Pathway, Mechanisms, and Kinetics. Ind Eng Chem Res 1999, 38(8): 2888-2895.

[36] Holgate HR, Meyer JC, Tester JW. Glucose hydrolysis and oxidation in supercritical water. AIChE J 1995, 41(3): 637-648.

[37] Lua AC, Yang T. Effect of activation temperature on the textural and chemical properties of potassium hydroxide activated carbon prepared from pistachio-nut shell. J Colloid Interf Sci 2004, 274(2): 594-601.

[38] Araujo-Andrade C, Ruiz F, Martínez-Mendoza JR, Terrones H. Infrared and Raman spectra, conformational stability, ab initio calculations of structure, and vibrational assignment of $\alpha$ and $\beta$ glucose. J Mol Struct: TEOCHEM 2005, 714(2-3): 143-146.

[39] Ibarra V, Muñoz E, Moliner R. FTIR study of the evolution of coal structure during the coalification process. Org Geochem 1996, 24(6-7): 725-735.

[40] Cuesta A, Dhamelincourt P, Laureyns J, Martínez-Alonso A, Tascón JMD. Raman microprobe studies on carbon materials. Carbon 1994, 32(8): 1523-1532.

[41] Sheng C. Char structure characterised by Raman spectroscopy and its correlations with combustion reactivity. Fuel 2007, 86(15): 2316-2324. 
[42] Ferrari AC, Robertson J. Interpretation of Raman spectra of disordered and amorphous carbon. Phys Rev B 2000, 61(20): 14095-14107.

[43] Schwan J, Ulrico S, Batori V, Ehrhardt H. Raman spectroscopy on amorphous carbon films. J Appl Phys 1996, 80(1): 440-447.

[44] Okpalugo TIT, Papakonstantinou P, Murphy H, McLaughlin J, Brown NMD. High resolution XPS characterization of chemical functionalised MWCNTs and SWCNTs. Carbon 2005, 43(1): 153-161.

[45] Molina R, Espinós JP, Yubero F, Erra P, González Elipe AR. XPS analysis of down stream plasma treated wool: Influence of the nature of the gas on the surface modification of wool. Appl Surf Sci 2005, 252(5): 1417-1429.

[46] Xia W, Wang Y, Bergsträßer R, Kundu S, Muhler M. Surface characterization of oxygen-functionalized multi-walled carbon nanotubes by high-resolution X-ray photoelectron spectroscopy and temperature-programmed desorption. Appl Surf Sci 2007, 254(1): 247-250.

[47] Sasaki M, Kabyemela B, Malaluan R, Hirose S, Takeda N, Adschiri T et al. Cellulose hydrolysis in subcritical and supercritical water. J Supercrit Fluids 1998, 13(1): 261-268.

[48] Sasaki M, Fang Z, Fukushima Y, Adschiri T, Arai K. Dissolution and Hydrolysis of Cellulose in Subcritical and Supercritical Water. Ind Eng Chem Res 2000, 39(8): 2883-2890.

[49] Ogihara Y, Smith Jr RL, Inomata H, Arai K. Direct observation of cellulose dissolution in subcritical and supercritical water over a wide range of water densities $\left(550-1000 \mathrm{~kg} / \mathrm{m}^{3}\right)$. Cellulose 2005, 12(6): 595-606.

[50] Tanger JC, Pitzer KS. Calculation of the Ionization Constant of $\mathrm{H}_{2} \mathrm{O}$ to $2273 \mathrm{~K}$ and 500 Mpa. AIChe J 1989, 35(10): 1631-1638. 
[51] Garrote G, Domínguez H., Parajó JC. Hydrothermal processing of lignocellulosic Materials. Holz als Roh- und Werkstoff 1999, 57(3): 191-202.

[52] Nagamori M, Funazukuri T. Glucose production by hydrolysis of starch under hydrothermal conditions. J Chem Technol Biotechnol 2004; 79(3): 229-233.

[53] Antal MJ, Mok WSL, Richards GN. Mechanism of formation of 5(hydroxymethyl)-2-furaldehyde from -fructose and sucrose. Carbohyd Res 1990, 199(1): 91-109.

[54] Sinag A, Kruse A, Schwarzkopf V. Formation and Degradation Pathways of Intermediate Products Formed during the Hydropyrolysis of Glucose as a Model Substance for Wet Biomass in a Tubular Reactor. Eng Life Sci 2003, 3(12): 469-473.

[55] Chheda JN, Huber GW, Dumesic JA. Liquid-Phase Catalytic Processing of Biomass-Derived Oxygenated Hydrocarbons to Fuels and Chemicals. Angew Chemie Int Ed 2007, 46(38): 7164-7183.

[56] Asghari FS, Yoshida H. Acid-Catalyzed Production of 5-Hydroxymethyl Furfural from d-Fructose in Subcritical Water. Ind Eng Chem Res 2006, 45 (7): 2163-2173.

[57] Luijkx GCA, van Rantwijk F, van Bekkum H, Antal Jr MJ. The role of deoxyhexonic acids in the hydrothermal decarboxylation of carbohydrates. Carbohyd Res 1995, 272(2): 191-202.

[58] Tang MM, Bacon R. Carbonization of cellulose fibers-II. Physical property study. Carbon 1964; 2 (3): 221-220. 
Table 1. Synthesis conditions, chemical elemental analysis and product yields for hydrochar materials obtained from the hydrothermal treatment of cellulose.

\begin{tabular}{|c|c|c|c|c|c|c|c|c|c|}
\hline \multirow{2}{*}{ Sample } & \multicolumn{3}{|c|}{ Synthesis conditions } & \multicolumn{5}{|c|}{ Chemical composition } & \multirow{2}{*}{ Yield $^{\mathrm{a}}$} \\
\hline & $\mathrm{T}\left({ }^{\circ} \mathrm{C}\right)$ & $C\left(g \cdot L^{-1}\right)$ & $\bar{t}(\mathrm{~h})$ & $\mathrm{C}$ (wt \%) & $\mathrm{H}(\mathrm{wt} \%)$ & $\mathrm{O}($ wt $\%)$ & $\mathrm{O} / \mathrm{C}$ (at.) & $\mathrm{H} / \mathrm{C}$ (at.) & \\
\hline Cellulose & - & - & - & 44.44 & 6.17 & 49.38 & 0.833 & 1.666 & - \\
\hline CE-1 & 230 & 40 & 4 & 71.35 & 4.34 & 24.31 & 0.256 & 0.730 & $33.5(53.8)$ \\
\hline CE-2 & 250 & 40 & 4 & 72.52 & 4.36 & 23.12 & 0.239 & 0.721 & 36.5 (59.6) \\
\hline CE-3 & 250 & 40 & 2 & 71.51 & 4.30 & 24.19 & 0.254 & 0.722 & $34.0(54.7)$ \\
\hline CE-4 & 250 & 160 & 4 & 71.66 & 4.55 & 23.79 & 0.249 & 0.762 & $52.3(84.3)$ \\
\hline CE-5 & 250 & 160 & 2 & 71.46 & 4.38 & 24.16 & 0.254 & 0.736 & $44.0(70.8)$ \\
\hline CE-6 & 250 & 320 & 2 & 70.72 & 4.48 & 24.80 & 0.263 & 0.760 & $42.7(68.0)$ \\
\hline
\end{tabular}

${ }^{a}$ The yield is expressed as: $\mathrm{g}$ product $/ 100 \mathrm{~g}$ cellulose. The percentage of $\mathrm{C}$ contained in the cellulose that is retained in the carbonized products is indicated in parentheses. 


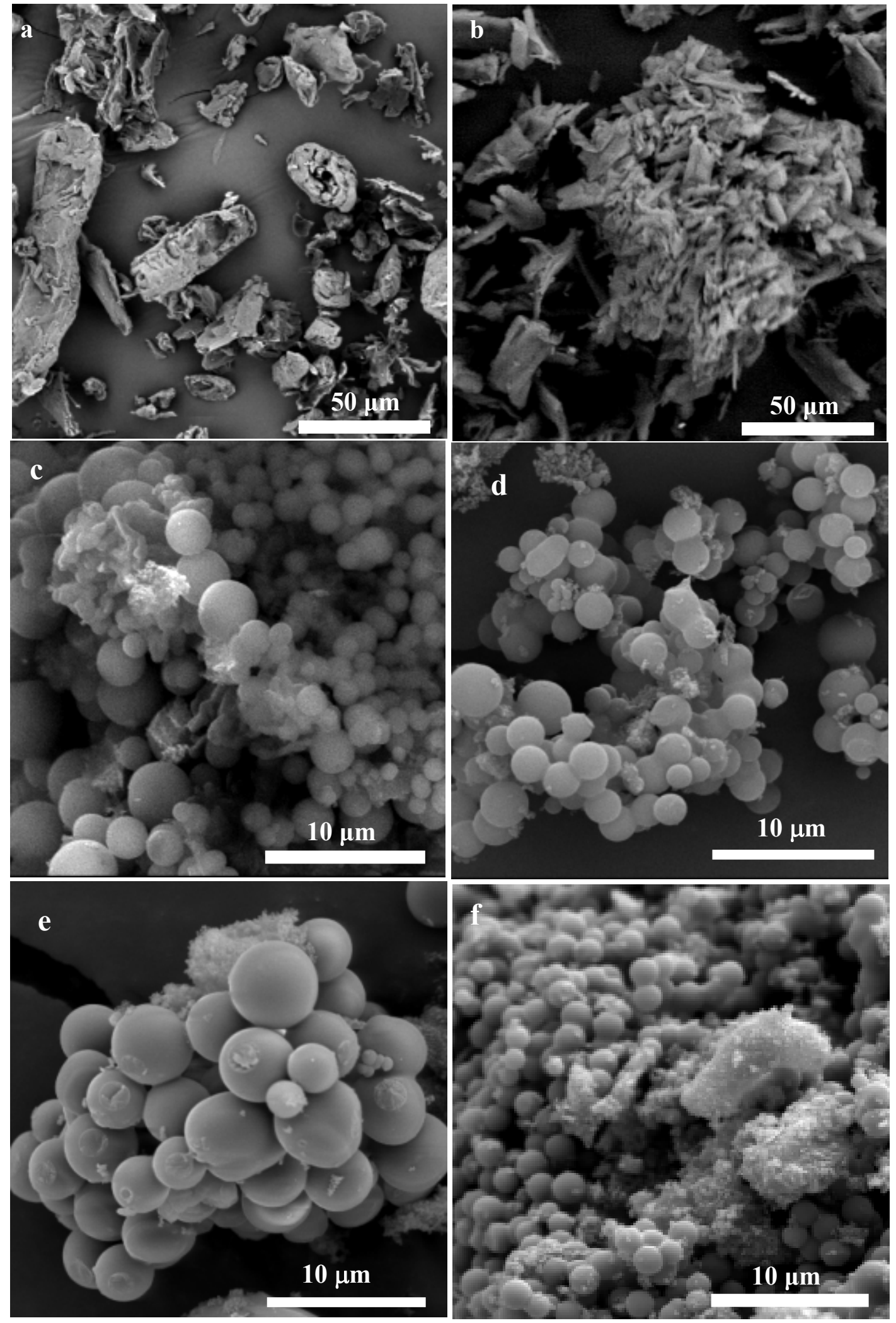

Figure 1. SEM images: (a) raw cellulose and (b-f) hydrothermally treated cellulose at: (b) $210^{\circ} \mathrm{C} / 40 \mathrm{~g} \cdot \mathrm{L}^{-1}$, (c) $220^{\circ} \mathrm{C} / 40 \mathrm{~g} \cdot \mathrm{L}^{-1}$, (d) $230^{\circ} \mathrm{C} / 40 \mathrm{~g} \cdot \mathrm{L}^{-1}(\mathrm{CE}-1)$, (e) $250^{\circ} \mathrm{C} / 40 \mathrm{~g} \cdot \mathrm{L}^{-1}$ (CE-3) and (f) $250^{\circ} \mathrm{C} / 160 \mathrm{~g} \cdot \mathrm{L}^{-1}(\mathrm{CE}-4)$. 


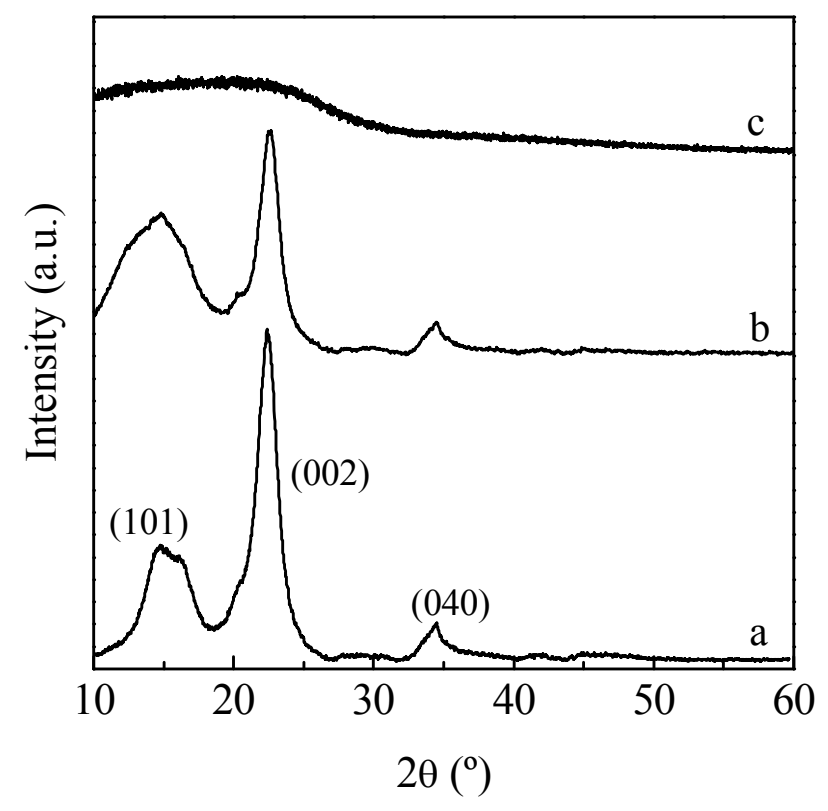

Figure 2. XRD patterns for (a) pristine cellulose and for the samples hydrothermally treated at (b) $210^{\circ} \mathrm{C}$ and (c) $220^{\circ} \mathrm{C}$. 


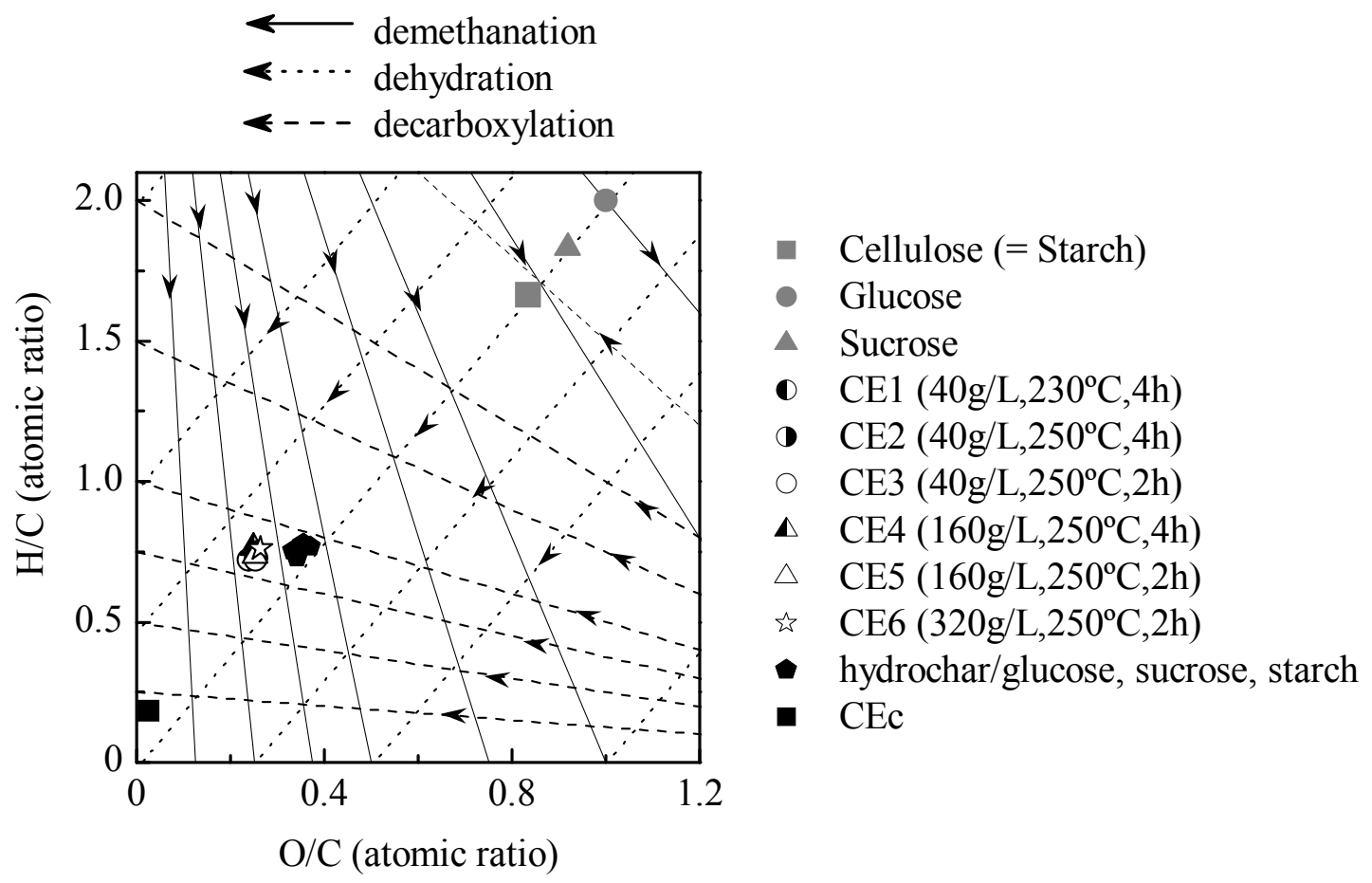

Figure 3. $(\mathrm{H} / \mathrm{C})-(\mathrm{O} / \mathrm{C})$ Van Krevelen diagram. This shows the $(\mathrm{H} / \mathrm{C})$ vs. $(\mathrm{O} / \mathrm{C})$ atomic ratios for: (a) cellulose and other saccharides, (b) the hydrochar products obtained from cellulose and (c) the carbonized material resulting from the pyrolysis of the cellulose at $700^{\circ} \mathrm{C}(\mathrm{CE}-\mathrm{c})$. 


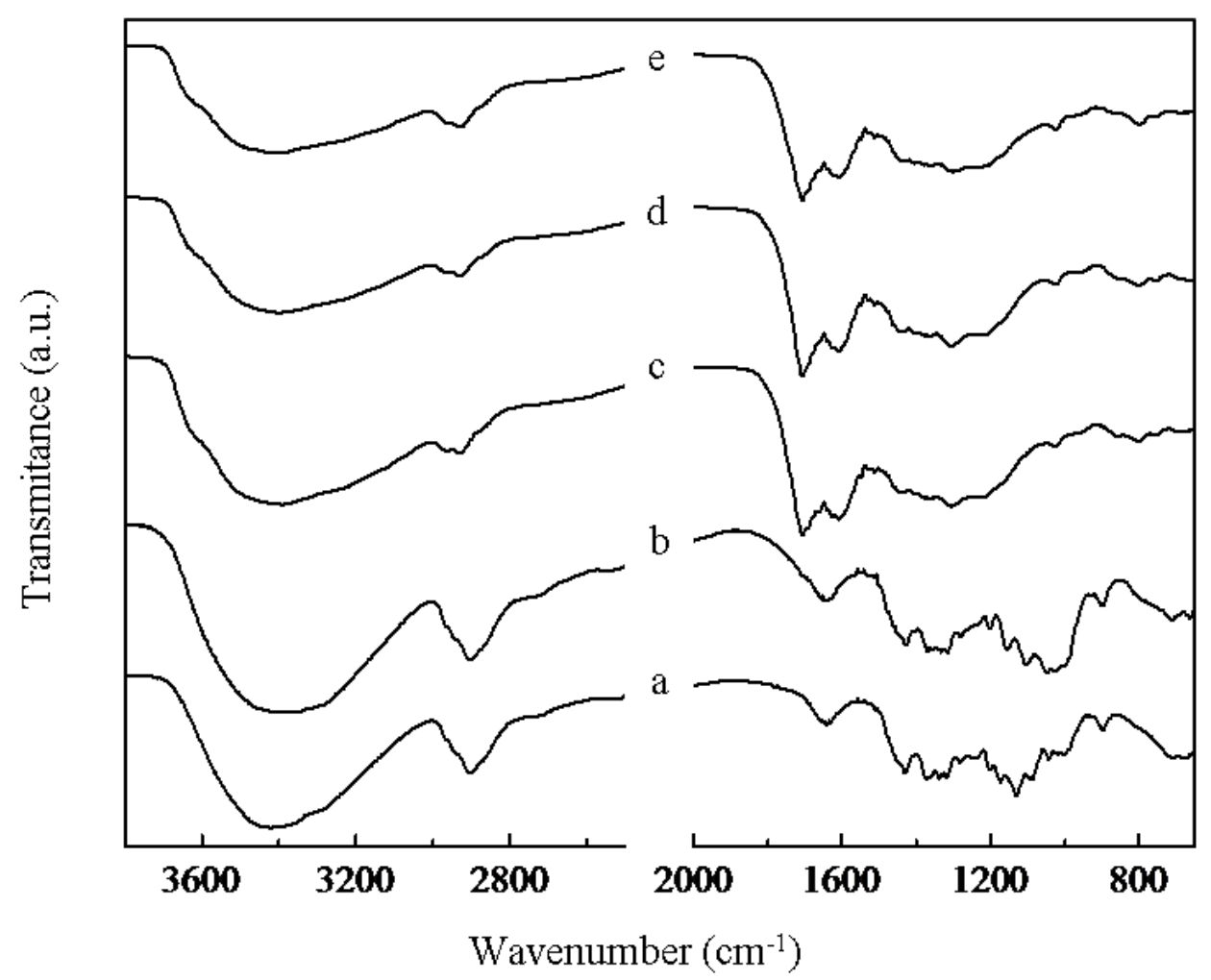

Figure 4. FTIR spectra for pristine cellulose (a), cellulose hydrothermally treated at $210^{\circ} \mathrm{C} / 40 \mathrm{~g} \cdot \mathrm{L}^{-1}$ (b), $220^{\circ} \mathrm{C} / 40 \mathrm{~g} \cdot \mathrm{L}^{-1}$ (c), $250^{\circ} \mathrm{C} / 40 \mathrm{~g} \cdot \mathrm{L}^{-1}(\mathrm{CE}-3)(\mathrm{d})$ and $250^{\circ} \mathrm{C} / 320 \mathrm{~g} \cdot \mathrm{L}^{-1}$ (CE-6) (e). 

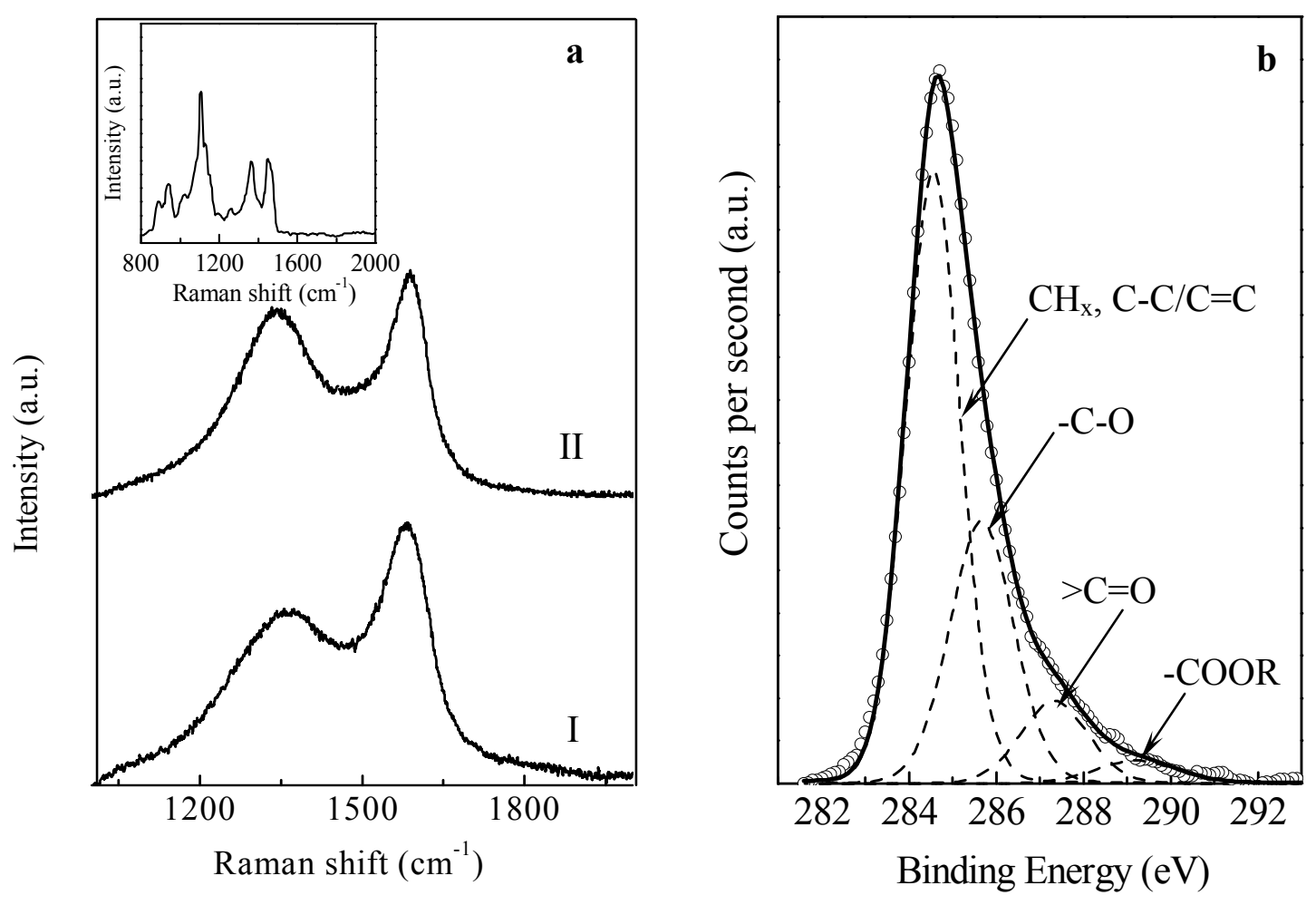

Figure 5. (a) Raman spectra of: (I) CE-4 hydrochar $\left(250^{\circ} \mathrm{C} / 4 \mathrm{~h}\right)$ and (II) the CE4 sample carbonized at $800^{\circ} \mathrm{C}$ ). Inset: Raman spectra of crystalline cellulose (Adapted from: N. Meyer et al., Fresenius J Anal Chem, 370, 789-791, 2001) (b) C 1s core level spectra of the CE-3 hydrochar sample $\left(250^{\circ} \mathrm{C} / 2 \mathrm{~h}\right)$. 


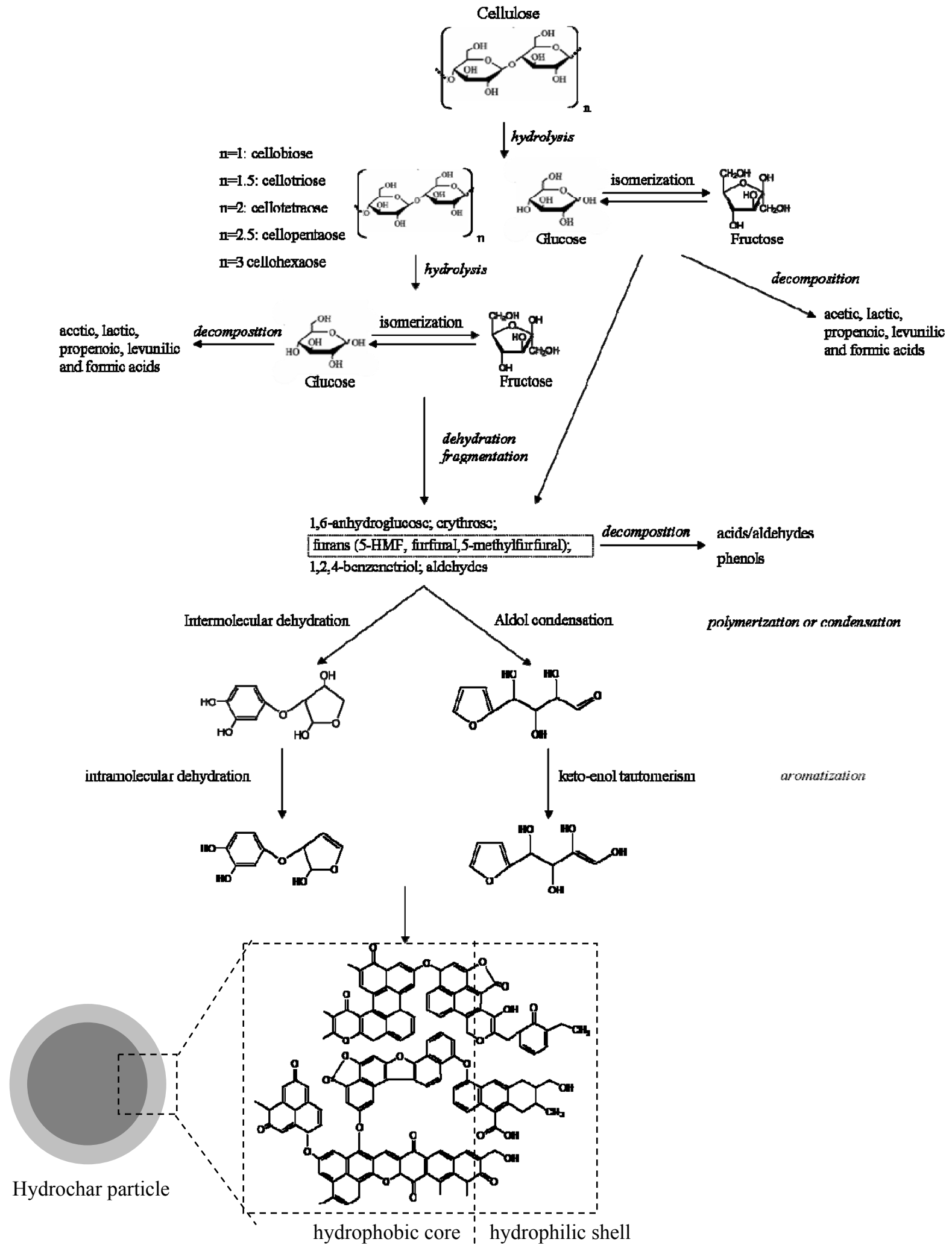

Figure 6. Mechanism of formation of hydrochar particles from cellulose by hydrothermal carbonization. 


\section{$\underline{\text { Supporting Information }}$}

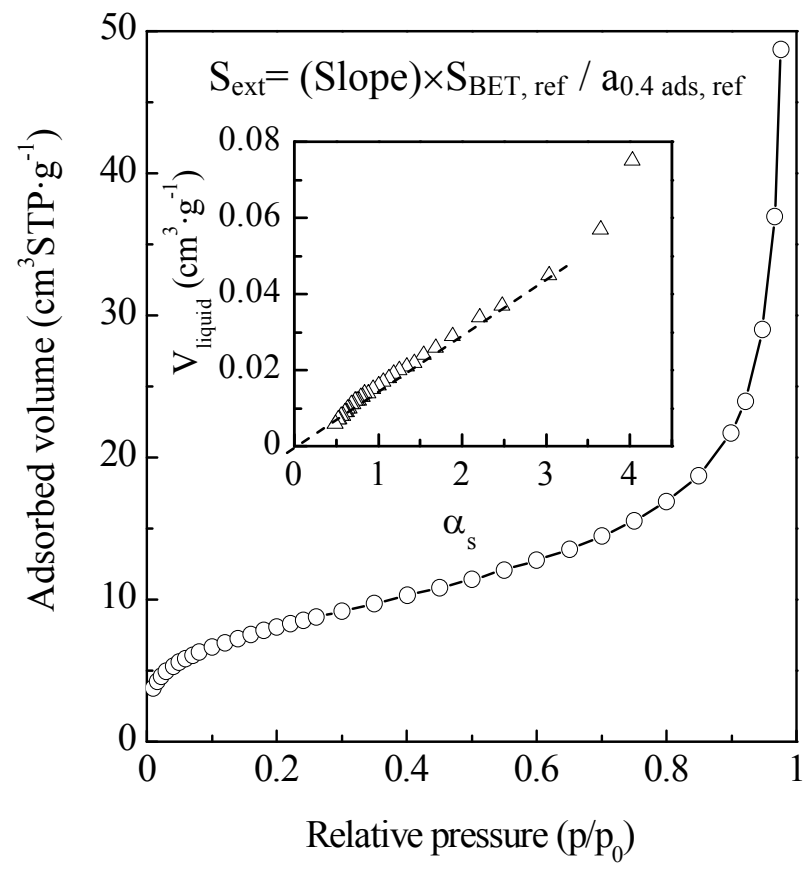

Figure S1. Nitrogen sorption isotherm of the CE-2 hydrochar sample. Inset: $\alpha_{\mathrm{s}}$-plot of the adsorption branch of the isotherm. The method used for the calculation of the external surface area is illustrated in Figure (a). $S_{B E T \text {, ref }}$ is the BET surface area of the material used as reference and $a_{0.4}$ ads, ref is the amount of nitrogen $\left(\mathrm{cm}^{3} \mathrm{~N}_{2}\right.$ liquid $\left.\cdot \mathrm{g}^{-1}\right)$ adsorbed by the reference solid at a relative pressure of 0.4 . For details see M. Kruk, M. Jaroniec, K. P. Gadkaree, J. Colloid. Interface Sci. 192 (1997) 250. 

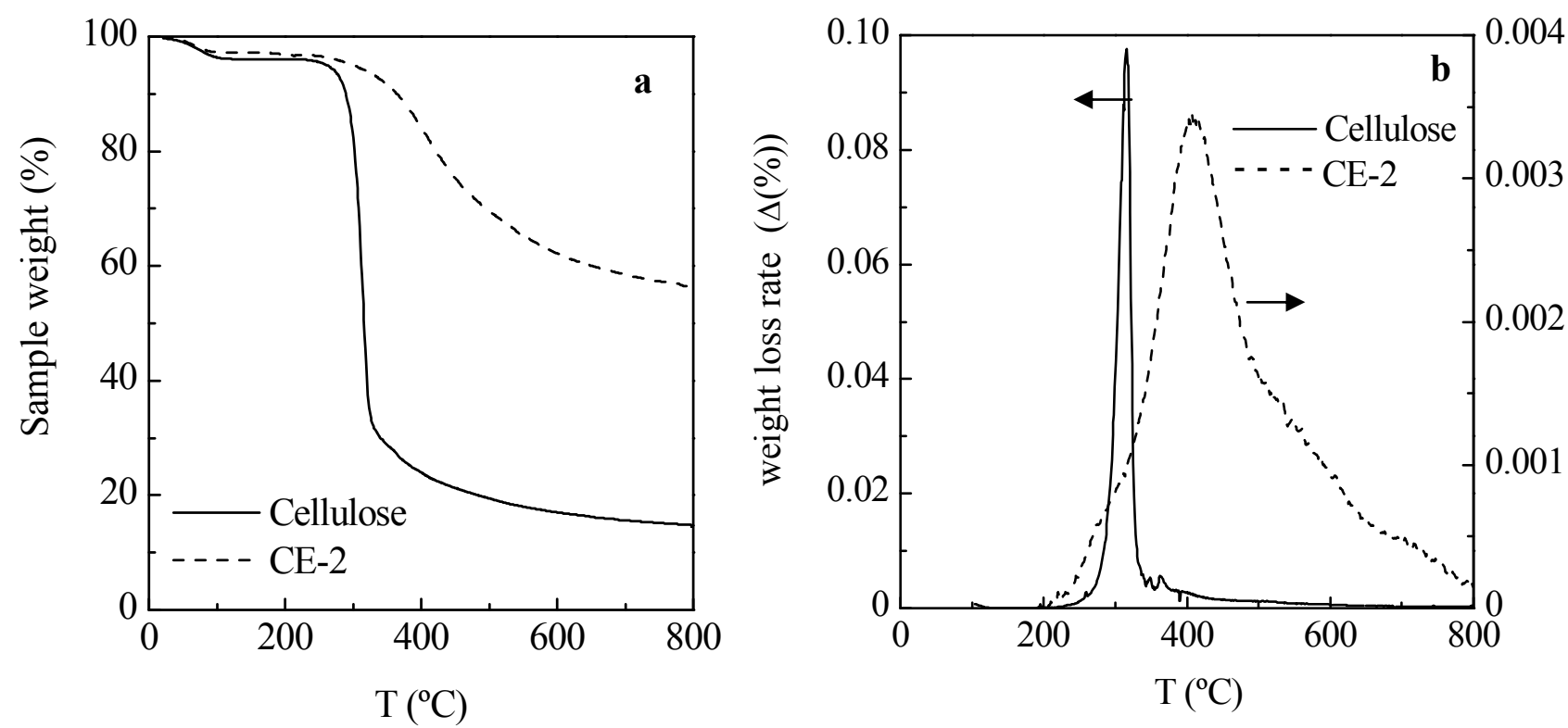

Figure S2. Variation of the sample weight (a) and the rate of sample weight loss (b) with temperature during the heat-treatment under nitrogen (carbonization) of the CE-2 hydrochar sample and cellulose. (Heating rate: $5^{\circ} \mathrm{C} \cdot \mathrm{min}^{-1}$ ). 